\title{
REVIEW
}

\section{Brazilian guidelines for the diagnosis and treatment of hereditary angioedema}

\author{
Pedro Giavina-Bianchi, ${ }^{1, I I}$ Alfeu T. França, ${ }^{\text {I,III }}$ Anete S. Grumach, ${ }^{\text {I,IV }}$ Abílio A. Motta, ${ }^{\mathrm{I}, \mathrm{II}}$ Fátima R. Fernandes,

 \\ 'Associação Brasileira de Alergia e Imunopatologia (ASBAI), São Paulo/SP, Brazil. "Division of Clinical Immunology and Allergy, Department of Internal \\ Medicine, University of São Paulo, São Paulo/SP, Brazil. "II Department of Clinical Immunology, Federal University of Rio de Janeiro, RJ, Brazil. IV Primary \\ Immunodeficiency Outpatient Group, Department of Dermatology, University of São Paulo, São Paulo/SP, Brazil. ${ }^{\circledR}$ Department of Allergy and Clinical

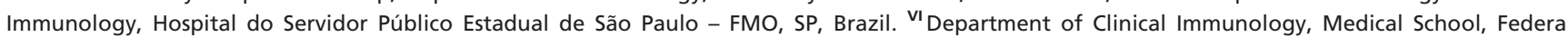 \\ University of Bahia, Salvador/BA, Brazil. VII Department of Pediatrics, Federal University of Paraná, Curitiba/PR, Brazil. VIII Division of Allergy, Clinical \\ Immunology and Rheumatology, Department of Pediatrics, Federal University of São Paulo-Paulista School of Medicine, São Paulo/SP, Brazil.
}

Hereditary angioedema is an autosomal dominant disease characterized by edema attacks with multiple organ involvement. It is caused by a quantitative or functional deficiency of the C1 inhibitor, which is a member of the serine protease inhibitor family. Hereditary angioedema is unknown to many health professionals and is therefore an underdiagnosed disease. The causes of death from hereditary angioedema include laryngeal edema with asphyxia. The estimated mortality rate in patients in whom the disease goes undetected and who are therefore incorrectly treated is $25-40 \%$. In addition to edema of the glottis, hereditary angioedema often results in edema of the gastrointestinal tract, which can be incapacitating. Patients with hereditary angioedema may undergo unnecessary surgical interventions because the digestive tract can be the primary or only organ system involved, thus mimicking acute surgical abdomen. It is estimated that patients with hereditary angioedema experience some degree of disability 20-100 days per year. The Experts in Clinical Immunology and Allergy of the "Associação Brasileira de Alergia e Imunopatologia - ASBAI" developed these guidelines for the diagnosis, therapy, and management of hereditary angioedema.

KEYWORDS: Hereditary angioedema; C1 inhibitor; Asphyxia; Acute surgical abdomen; Guidelines; Consensus.

Giavina-Bianchi P, França AT, Grumach AS, Motta AA, Fernandes FR, Campos RA. Brazilian guidelines for the diagnosis and treatment of hereditary angioedema. Clinics. 2011;66(9):1627-1636.

Received for publication on April 27, 2011; First review completed on April 28, 2011; Accepted for publication on May 1, 2011

E-mail: saudesos@saudesos.com.br

Tel.: 551130713189

\section{DEFINITION}

What is hereditary angioedema?

Hereditary angioedema (HAE) is an autosomal dominant disease that is characterized by edema attacks with multiple organ involvement. It is caused by quantitative or functional deficiency of the $\mathrm{C} 1$ inhibitor (C1-INH), which is a member of the serine protease inhibitor family.

\section{INTRODUCTION}

Why should we study HAE?

HAE was first described as a clinical entity by Quincke in 1882, and its hereditary nature was established by Osler in 1888. ${ }^{1,2}$ The biochemical change associated with HAE, C1INH deficiency, was not identified until 75 years later, in $1963 .^{3}$

Copyright (c) 2011 CLINICS - This is an Open Access article distributed under the terms of the Creative Commons Attribution Non-Commercial License (http:// creativecommons.org/licenses/by-nc/3.0/) which permits unrestricted noncommercial use, distribution, and reproduction in any medium, provided the original work is properly cited.
Sir William Osler (1849-1919), a Canadian physician who lived in the United States and England, was renowned for his many contributions to medicine, including his participation in the description of HAE and for stating that "Medicine is both a Science and an Art". To develop evidence-based guidelines is to practice medicine as a science. To follow such guidelines and consensuses while treating patients and their various phenotypes in a personalized manner is to practice medicine as an art.

HAE is a disease that is unknown to many health professionals and is therefore underdiagnosed. The prevalence of HAE is approximately 1:50,000 (with estimates ranging from $1: 10,000$ to $1: 150,000)$; the disease affects various ethnic groups and accounts for $2 \%$ of all cases of angioedema. ${ }^{4-7}$

As is true for other autosomal dominant diseases, the children of a patient with HAE have a $50 \%$ chance of carrying the anomalous gene. Although a family history is characteristic of the disease and should alert physicians to a possible diagnosis of $\mathrm{HAE}$, in $20-25 \%$ of cases, a family history of disease is absent, and new, spontaneous mutations can be observed. ${ }^{8}$ Approximately 200 HAE-associated mutations have been identified to date. Although genetic defects are found in patients of both genders with equal 
frequency, the phenotype is more common in female patients, for whom the disease is more severe. ${ }^{9}$

The time elapsed between the onset of symptoms and diagnosis, as well as the time between diagnosis and the initiation of treatment, play important roles in HAE-related morbidity and mortality. ${ }^{10-13}$ Therefore, physicians should be aware of the clinical profile and laboratory tests that confirm a diagnosis of HAE and inform decisions regarding its treatment.

The cause of death from HAE is laryngeal edema with asphyxia, and the estimated mortality rate in patients in whom the disease goes undetected and who are therefore incorrectly treated is $25-40 \% .^{7,10-15}$ Patients with HAE are commonly hospitalized and admitted to intensive care units, and the disease accounts for 15,000-30,000 emergency room visits per year in the United States. ${ }^{16}$

The two most severe clinical manifestations of HAE are edema of the larynx and edema of the bowel wall. Delayed diagnosis increases morbidity, thereby affecting the quality of life of patients and their families. ${ }^{17,18}$ A study involving two families showed that nine out of ten family members who were hospitalized for symptoms of HAE were discharged with diagnoses other than HAE. ${ }^{19}$

In addition to life-threatening edema of the glottis, HAE often results in edema of the gastrointestinal tract, which can be incapacitating. Patients with HAE may undergo unnecessary surgical interventions because the digestive tract can be the primary or only organ system involved, thus mimicking acute surgical abdomen. ${ }^{20,21}$ It is estimated that patients with HAE experience some degree of disability 20100 days per year. ${ }^{17}$

\section{PATHOPHYSIOLOGY}

\section{What is the cause of HAE?}

Patients with HAE present with a quantitative or qualitative deficiency of $\mathrm{C} 1-\mathrm{INH}$, which is a serine protease inhibitor. This enzyme inhibits the C1r and C1s esterases, which bind to and activate C1q. Without such inhibition, the complement system becomes excessively activated. ${ }^{22,23}$

C1-INH also inhibits the lectin pathway of complement system activation and participates in the regulation of the contact, coagulation, and fibrinolysis systems. Deficiency of C1-INH results in increased bradykinin production.

Episodes of angioedema were initially attributed to factors that were formed during complement system activation, including a C2 fragment (C2 kinin) that is associated with vasodilation and increased vascular permeability. ${ }^{24}$ Recent evidence has shown that bradykinin is one of the principal mediators of HAE. ${ }^{25-27}$

It has been shown that bradykinin levels are higher in blood drawn from angioedematous sites than in blood drawn from the systemic circulation. ${ }^{25}$ Knockout mice with concomitant deficiencies of $\mathrm{C} 1-\mathrm{INH}$ and bradykinin receptor B2 (BDKRB2) display decreased vascular permeability, which demonstrates that the bradykinin/BDKRB2 pathway plays an important role in the development of angioedema. ${ }^{26}$

\section{CLASSIFICATION}

\section{What are the types of HAE?}

Currently, HAE is divided into three groups (Table 1). Most patients $(80-85 \%)$ present with type I HAE, with reduced C1-INH synthesis (a quantitative defect). ${ }^{28}$ Low serum levels of C1-INH trigger the attacks.

In patients who present with type II HAE (15-20\%), adequate quantities of $\mathrm{C} 1$-INH are produced, although the functional capacity of the protein is partially diminished. ${ }^{29}$ Therefore, the enzyme has a qualitative (i.e., functional) defect.

Type III HAE is rarer than types I and II and principally affects females. It is characterized by normal C1-INH levels and activity. ${ }^{30}$ This group includes diseases that vary in their etiopathogenesis; coagulation disorders and links to the endocrine system have been identified in this group. ${ }^{9,31,32}$

Acquired angioedema (AAE), which has a manifestation similar to that of HAE, is noteworthy among the differential diagnoses of HAE. ${ }^{33}$ AAE is characteristically associated with lymphoproliferative and autoimmune diseases in which there is consumption of C1-INH, which is caused by the activation of C1-INH or by the production of anti-C1INH autoantibodies. ${ }^{34}$

\section{DIAGNOSIS}

What is the typical clinical manifestation of HAE?

The patient's clinical history is the principal component of an HAE diagnosis. Patients with HAE present with attacks of nonpruritic edema of the skin and submucosa that affects various organs. ${ }^{11-13}$ The most commonly affected sites are the face, extremities, genitalia, oropharynx, larynx, and digestive system. However, rarer clinical manifestations, including intense headaches caused by brain edema, urinary retention, and acute pancreatitis, can also occur. ${ }^{12,35}$

The incidence and severity of the clinical manifestations of HAE vary among individuals. It has been reported that $5 \%$ of patients with HAE are asymptomatic, and $25 \%$ develop sporadic symptoms. ${ }^{6,11,12,36-38}$ A retrospective study analyzing 131,110 attacks in 221 patients with HAE reported that laryngeal edema occurred in less than $1 \%$ of the attacks, although over $50 \%$ of the patients had previously experienced that symptom at least once. ${ }^{12}$

Left untreated, HAE attacks typically last 48-72 h. Although many attacks occur spontaneously, a number of triggering factors have been identified, including minor trauma, stress, infection, menstruation, pregnancy, alcohol consumption, a change in temperature, exercise, the use of angiotensin-converting enzyme (ACE) inhibitors, and the use of estrogen (including contraceptives and hormone replacement therapy). 6,11,12,36-39

Serpiginous erythema can occur as a prodromal manifestation that precedes angioedema in some patients; however, the concomitant presence of pruritic urticaria makes the diagnosis of HAE unlikely. ${ }^{6,11,12,36-38}$ However, some cases of HAE coexisting with urticaria have been reported. ${ }^{40}$

A family history of clinical manifestations that are similar to those seen in the patient supports a diagnosis of HAE, although this type of family history is absent in approximately $25 \%$ of cases. ${ }^{8}$

In children, the clinical manifestations of HAE generally develop before six years of age. However, the onset of clinical manifestations in infants is rare, and few cases have been described. Attacks of laryngeal edema are particularly rare before three years of age and tend to occur later than other manifestations. During adolescence, there are substantial changes in disease activity, particularly in girls, for 
Table 1 - Classification of hereditary angioedema.

\begin{tabular}{ll}
\hline TYPE & \multicolumn{1}{c}{ DEFECT } \\
\hline Type I - Quantitative & Decreased C1 inhibitor synthesis \\
Type II - Functional; Qualitative & Decreased C1 inhibitor function \\
Type III & Normal C1 inhibitor levels and function \\
& A- Estrogen-dependent or estrogen-related \\
& B- Mutation of factor XII (Hageman factor) \\
\hline
\end{tabular}

whom disease progression is worse because of their menstrual cycles and their use of contraceptives containing estrogen. $6,11,12,36-38$

Although the manifestations of type III HAE are similar to those of the other HAE types, there are certain features unique to this type. Symptom onset generally occurs later in life, the course of the disease tends to be more benign, and tongue involvement is common. Purpura is occasionally seen at sites that are affected by angioedema. However, the most striking characteristic of type III HAE is a personal and family history of associations between the disease and female gender and between the disease and estrogen administration.

In $\mathrm{AAE}$, the onset of symptoms also occurs later, there is no family history of angioedema, and the associations between AAE and lymphoproliferative diseases and between AAE and autoimmune diseases should be investigated. $^{33,34}$

\section{How can laboratory tests confirm the diagnosis of HAE?}

Individuals who are clinically suspected of having HAE and individuals with a family history of HAE should be investigated (Table 2). The principal screening test is the determination of serum levels of $\mathrm{C}^{6}$. $^{6,36-38}$

Quantitative or qualitative C1-INH deficiency leads to the permanent activation of the complement system, accompanied by $\mathrm{C} 4$ consumption, even when patients are not experiencing an angioedema attack. In $2-5 \%$ of cases, C4 levels normalize during the intercrisis period. ${ }^{41}$

C3 turnover is greater than C4 turnover. In addition, there are other proteins that, together with $\mathrm{C} 1-\mathrm{INH}$, regulate the consumption of C3, the levels of which are generally normal in HAE patients. Therefore, the determination of C3 levels is unnecessary except in patients who are suspected of having AAE, principally in the presence of autoimmune diseases. ${ }^{6,36-38}$ In AAE, there is activation and consumption of complement components, and $75 \%$ of patients present with reduced serum levels of $\mathrm{C} 1 \mathrm{q} .{ }^{42}$ Therefore, the determination of $\mathrm{C} 1 \mathrm{q}$ levels can aid in the differentiation between HAE and AAE.
Following (or concomitant with) the determination of serum levels of C4, quantitative and qualitative determinations of C1-INH should be performed. All health professionals and family members who are involved in providing care for patients with HAE must ensure that such tests are available. Although the quantitative determination of C1INH is a relatively easy test to perform, the determination of functional enzymatic activity (qualitative test) should be performed at a referral laboratory. ${ }^{6,36-38}$ Importantly, the determination of functional activity is only necessary when C1-INH levels are normal (Figure 1).

If clinical suspicion remains despite normal C4 levels and normal (quantitative/qualitative) C1-INH levels, these tests should be performed again during an angioedema attack. ${ }^{6,36-38}$ If the test results are again normal, a diagnosis of type III HAE is suggested. ${ }^{30}$

\section{What are the diagnostic criteria for HAE?}

Criteria to standardize the diagnosis of HAE have been proposed (Table 3). ${ }^{36}$ According to these criteria, the presence of HAE is confirmed when patients meet one major clinical criterion and one biochemical criterion.

It should be noted that those criteria are not absolute and that the patient's clinical history takes precedence, principally in locations where the laboratory tests are not available and in suspected cases of type III HAE. In selected cases, we can presume a diagnosis of HAE and perform a therapeutic test.

\section{TREATMENT}

\section{Guidance}

To improve the quality of life of patients and their families and to avoid severe complications, the most important initial measure is to provide guidance regarding the course of HAE and the triggering factors for attacks. Patients should be given relevant information (in writing) regarding the disease and the steps that must be taken in the case of an attack (an action plan). There are nonpharmacological approaches that can reduce HAE severity and therefore merit attention.

Table 2 - Laboratory diagnosis of angioedema.

\begin{tabular}{|c|c|c|c|c|c|}
\hline Type of Angioedema & C1-INH level & C1-INH function & C4 & C3 & $\mathrm{C} 1 \mathrm{q}$ \\
\hline Type I HAE & Low & Low & Low & Normal & Norma \\
\hline Type II HAE & Normal & Low & Low & Normal & Norma \\
\hline Type III HAE & Normal & Normal & Normal & Normal & Norma \\
\hline AAE & Low & Low & Low & Normal/Low & Low \\
\hline ACE inhibitor & Normal & Normal & Normal & Normal & Norma \\
\hline Idiopathic & Normal & Normal & Normal & Normal & Norma \\
\hline
\end{tabular}

C1-INH: C1 inhibitor, HAE: hereditary angioedema, AAE: acquired angioedema, ACE: angiotensin-converting enzyme. 


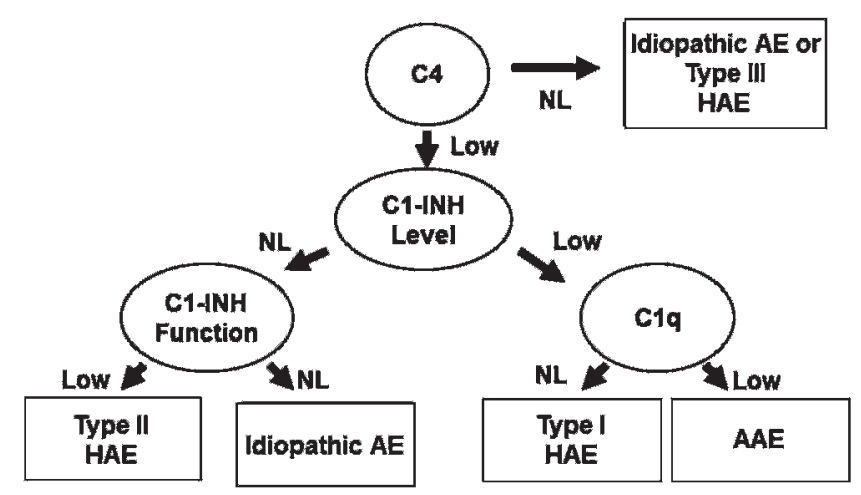

Figure 1 - Diagnostic algorithm of hereditary angioedema. C1INH: C1 inhibitor, HAE: hereditary angioedema, AAE: acquired angioedema, NL: normal.

Because of the significant morbidity and mortality associated with HAE, a strategy involving careful treatment and prevention of attacks is essential for appropriate patient management (Table 4). The experience at large centers has demonstrated that $25-40 \%$ of patients can develop asphyxia and die if they are left untreated. ${ }^{7,10-15}$

\section{Prevention of attacks}

The risk of attacks can be reduced by identifying and eliminating the factors that trigger them. Stress and trauma are clearly triggering factors for edema in HAE, so patients should monitor those factors. High-impact sports and hobbies that pose a risk of trauma should be avoided. To prevent infections, which constitute a trigger of attacks, immunization is indicated. Hepatitis B vaccination is recommended because blood products might be used during the treatment of HAE attacks. ${ }^{43}$

\section{Drugs that can worsen or prolong an HAE attack}

The drugs that most commonly worsen or prolong the clinical profile of HAE or AAE are ACE inhibitors, angiotensin II receptor antagonists, medications containing estrogen, and certain oral hypoglycemic agents.

Because ACE inhibitors increase the half-life of bradykinin, their use should be avoided. ${ }^{44}$ Angiotensin II receptor antagonists can also worsen the clinical profile of HAE, although they do so less commonly than ACE inhibitors. ${ }^{45}$

Contraceptives containing progesterone should be preferentially prescribed over those containing estrogen. ${ }^{16,46}$

Sitagliptin phosphate, which is an oral hypoglycemic agent indicated for the treatment of type 2 diabetes, belongs to a class of oral hypoglycemic agents designated dipeptidyl

Table 3 - Diagnostic criteria for hereditary angioedema. ${ }^{36}$

I - Primary clinical criteria

a) Non-inflammatory subcutaneous angioedema

lasting longer than $12 \mathrm{~h}$

b) Abdominal pain of undefined organic etiology lasting longer than $6 \mathrm{~h}$

c) Recurrent laryngeal edema

II - Secondary clinical criteria

a) Family history of hereditary angioedema

III - Biochemical criteria

a) Quantitative $\mathrm{C} 1$ inhibitor $<50 \%$ in two distinct samples

b) Functional $\mathrm{C} 1$ inhibitor $<50 \%$ in two distinct samples

c) Mutation in the $\mathrm{C} 1$ inhibitor gene
Table 4 - General recommendations for the medical treatment of attacks of hereditary angioedema.

Take a personal and family history of the acute attack profile
Use oxygenation and pulse oximetry
Hydrate
Use antispasmodics and analgesics as needed
Avoid the use of angiotensin-converting enzyme inhibitors
Increase the dose of chronic medication to control the attack
Use acute phase control agents (fresh plasma, C1 inhibitor, bradykinin
receptor antagonist, or kallikrein inhibitor) if available

peptidase- 4 inhibitors, which can worsen the clinical profile of HAE. ${ }^{47}$

\section{Genetic screening of family members}

All first-degree relatives of patients with HAE should be screened for HAE. In pediatric patients with a family history of HAE, the HAE diagnostic tests should be performed at six months of age and repeated at one year. ${ }^{48}$

Patients and their families should receive genetic counseling and guidance regarding the inheritance pattern of the disease. ${ }^{49}$

\section{Pharmacological treatment}

The pharmacological treatment of HAE can be divided into three modalities: long-term prophylaxis, short-term prophylaxis, and treatment of attacks.

The therapies recommended here were classified according to the strength of the recommendation, which is based on the level of scientific evidence supporting such a recommendation (Table 5).

\section{How should long-term prophylaxis be performed?}

The objective of long-term prophylaxis in HAE is to reduce the frequency and severity of attacks. These two variables can vary widely. Patients may be asymptomatic or experience attacks twice per week with symptoms that are practically continuous. Therefore, the first question regarding long-term prophylaxis should be whether patients actually require this type of treatment.

In general, individuals with frequent symptoms or a history of angioedema attacks involving the upper airways should be treated prophylactically. Patients who are candidates for this type of treatment are those who present with more than one severe attack per month or those who experience more than five attacks per month. 6,36-38

Although the number and severity of angioedema attacks play important roles in this evaluation, the impact of angioedema episodes on the patient's quality of life is a decisive aspect. Another important point to be considered is whether patients have access to appropriate medical care in the case of a severe episode of angioedema. ${ }^{50}$

In Brazil, two treatment modalities are available for longterm prophylaxis: attenuated androgens and antifibrinolytic agents.

The most effective and best tolerated therapy for longterm prophylaxis of HAE is attenuated androgens that increase the levels of $\mathrm{C} 1-\mathrm{INH}$ and $\mathrm{C} 4$ and reduce the number of attacks of angioedema (grade B recommendation). ${ }^{51}$ The drugs used include danazol, stanozolol, and oxandrolone, which are less virilizing than methyltestosterone. Oxandrolone is especially recommended for use in children. $^{52}$ 
Table 5 - Evidence levels and degrees of recommendation for therapies.

\begin{tabular}{|c|c|}
\hline \multicolumn{2}{|c|}{ Levels of evidence } \\
\hline Level & Meaning \\
\hline 1 & $\begin{array}{c}\text { One or more randomized controlled clinical trials of sufficient } \\
\text { sample size with a narrow confidence interval } \\
\text { Meta-analysis of randomized controlled clinical trials }\end{array}$ \\
\hline 2 & $\begin{array}{l}\text { Good quality cohort study } \\
\text { Low-quality randomized clinical trial (small sample size and } \\
>20 \% \text { lost to follow-up) }\end{array}$ \\
\hline 3 & $\begin{array}{c}\text { Case-control studies } \\
\text { Meta-analysis of case-control studies }\end{array}$ \\
\hline 4 & $\begin{array}{c}\text { Case series } \\
\text { Low-quality cohort studies } \\
\text { Low-quality case-control studies }\end{array}$ \\
\hline 5 & Based on expert opinions, experimental studies or physiology \\
\hline \multicolumn{2}{|c|}{ Grade/Strength of recommendation } \\
\hline Grade & Meaning \\
\hline A & Corresponding to level of evidence 1 \\
\hline B & $\begin{array}{c}\text { Corresponding to level of evidence } 2 \text { or } 3 \\
\text { Extrapolated from level } 1 \text { studies involving populations other } \\
\text { than the current population }\end{array}$ \\
\hline C & $\begin{array}{c}\text { Corresponding to level of evidence } 4 \\
\text { Extrapolated from level } 2 \text { or } 3 \text { studies involving populations } \\
\text { other than the current population }\end{array}$ \\
\hline D & Corresponding to level of evidence 5 \\
\hline
\end{tabular}

Adapted from: Levels of evidence and grades of recommendation, Oxford Center for Evidence-Based Medicine, May 2001.

http://www.cebm.net/levels_of_evidence.

In Brazil, the most widely used attenuated androgen is danazol, which is also the most widely available (its availability is guaranteed by the High-Cost Drug Program); in addition, well-controlled studies have demonstrated the clinical efficacy of this drug and have shown that it improves biochemical parameters. ${ }^{51,53,54}$

Treatment with danazol can be started at high doses (600 $\mathrm{mg}$ /day), which can later be reduced. Another option is to start at a low dose (50-200 mg) and increase the dose as needed. Therefore, two protocols have been established: ${ }^{6}$

a) Milan Protocol-Initiation at a high dose with a subsequent reduction:

- 400-600 mg/day of danazol for one month

- Wean by 1/3, or $100 \mathrm{mg}$, every month

- At $200 \mathrm{mg} /$ day, taper by $50 \mathrm{mg}$ every two months

- At $100 \mathrm{mg} /$ day, taper by $50 \mathrm{mg}$ every three months

- Minimum dose of $50 \mathrm{mg} /$ day, five days per week

- If the symptoms recur, re-induce remission with the initial dose and wean to a higher maintenance dose than the previously administered dose.

b) Budapest Protocol-Initiation at a low dose with a subsequent increase:

- $2.5 \mathrm{mg} / \mathrm{kg}$ of danazol (maximum of $200 \mathrm{mg}$ ) administered daily for one month

- If there is no response, increase to $300 \mathrm{mg} /$ day for two-four weeks
- If there is no response, increase to $400 \mathrm{mg} /$ day for two-four weeks

- If controlled at $200 \mathrm{mg}$, reduce to $100 \mathrm{mg} /$ day for one month

- If controlled at $100 \mathrm{mg}$, reduce to $50 \mathrm{mg} /$ day or $100 \mathrm{mg}$ on alternate days

- If there are prodromal symptoms of attack, double the dose for several days.

The best strategy should be chosen based on the patient's clinical status. Therefore, we should consider whether it is more important to control the angioedema attacks as fast as possible or to minimize the potential adverse effects of the drug. In both protocols, the final dose should be the lowest dose that provides adequate prophylaxis, generally ranging from the administration of 50 to $200 \mathrm{mg}$ /day or on alternate days.

Although androgens increase the levels of C1-INH and C4, symptomatic benefits are generally achieved at doses lower than those required to significantly alter the levels of complement components. Therefore, it is important that the drug dosage is based on the patient's clinical symptoms rather than his or her biochemical parameters. It should be emphasized that androgens are ineffective in controlling attacks of HAE because it takes approximately $48 \mathrm{~h}$ for the drugs to begin to take effect. ${ }^{55}$

Most patients tolerate androgens at the aforementioned doses. However, sustained use at higher doses generally results in significant adverse effects. The adverse effects of androgens are related to the dosage, with the major adverse effects being hepatotoxicity and virilization. ${ }^{56}$

Other adverse reactions include weight gain, headache, menstrual changes, acne, changes in libido, anxiety, mood disorders, hypertension, myopathy, changes in lipid profiles, and hematuria. ${ }^{57}$ Although there is evidence of changes in patients' lipid profiles, the association between danazol and atherosclerosis is controversial. ${ }^{57-59}$ Danazolinduced hematuria results from mild cystitis or bladder telangiectasia. ${ }^{60}$ These adverse effects tend to disappear after the discontinuation of the drug.

In individuals receiving androgens, the hepatic enzyme levels should be evaluated every six months. If liver damage develops, the dose should be reduced or the drug should be discontinued until these tests yield normal results.

Because hepatic adenomas and hepatocellular carcinoma have previously been reported as consequences of the use of androgens, liver ultrasounds should also be routinely performed every six months. ${ }^{61,62}$ The development of liver tumors in patients who are using danazol has been associated with the use of higher doses (400-800 mg), a longer duration of administration, and the lack of monitoring for liver injury. ${ }^{63}$

Although many patients complain of androgen-induced adverse events, most patients with HAE can benefit, at least moderately, from androgen use, and the risk profile is acceptable.

Danazol is contraindicated during pregnancy because there have been documented cases of virilization in female neonates. However, discontinuation of the drug by gestational week eight has been shown to avert that alteration. ${ }^{64-66}$ Other contraindications for danazol use include breastfeeding and prostate cancer, as well as kidney, liver, and heart failure. 
Antifibrinolytic agents (epsilon-aminocaproic acid and tranexamic acid) are generally effective (grade B recommendation) in preventing HAE attacks. ${ }^{67-71}$ These drugs antagonize the fibrinolytic system by blocking plasmin formation and inhibiting the proteolytic activity of plasminogen activators and, consequently, clot dissolution. The mechanism by which antifibrinolytic agents prevent HAE attacks remains unknown. Unlike attenuated androgens, antifibrinolytic agents do not increase the serum levels of C1-INH or C4.

The therapeutic dose of epsilon-aminocaproic acid is $1 \mathrm{~g}$, administered orally three to four times per day, and it can be as high as $8 \mathrm{~g} /$ day. $^{55}$ Tranexamic acid should be administered at a dose of $0.5-0.75 \mathrm{mg} / \mathrm{kg}$ two to three times per day; the drug is more potent than aminocaproic acid and has a lower incidence of adverse effects. ${ }^{72}$ The side effects of antifibrinolytic agents include nausea, diarrhea, vertigo, postural hypotension, fatigue, muscle weakness, cramps, and increased muscle enzyme levels. ${ }^{50}$ Other adverse effects that are associated with the inhibition of plasmin include the increased occurrence of thrombosis and increased tumor growth. Because of the risks of teratogenicity, the use of antifibrinolytic agents during pregnancy is restricted. ${ }^{50}$

As occurs with attenuated androgens, the time of onset of the therapeutic effects of antifibrinolytic agents is approximately $48 \mathrm{~h}$ after administration. Therefore, both classes of drugs are of little use in providing immediate symptom relief. Because anabolic androgens are more effective in controlling HAE, they generally constitute the treatment of choice (grade $\mathrm{C}$ recommendation). Antifibrinolytic agents should be reserved for patients who do not tolerate anabolic androgens or for cases in which anabolic androgens are contraindicated. In severe cases for which the maximum dose of androgen is not sufficient to control the attacks, antifibrinolytic agents can be used in combination with androgens.

Long-term prophylaxis of HAE is satisfactory for most patients but has the disadvantage of requiring daily medication. In some patients, the use of androgens or antifibrinolytic agents is impractical because of the adverse reactions that they provoke (principally in females) or because of a lack of response. In addition, neither class of drugs is safe for use during pregnancy.

Although they are still unavailable in Brazil, C1-INH concentrates, which have a grade $\mathrm{B}$ recommendation, have been used elsewhere for the long-term prophylaxis of HAE. ${ }^{73-75}$ Administered intravenously at regular intervals, approximately three times per week, C1-INH concentrates constitute a viable therapeutic alternative for individuals in whom other therapies cannot be used or are ineffective.

Regardless of the drug chosen, the effectiveness of each drug depends on treatment adherence, which must be encouraged and evaluated.

\section{How should short-term prophylaxis be performed?}

Short-term prophylaxis is indicated for patients undergoing major surgical procedures (e.g., surgery with orotracheal intubation), other surgical procedures (principally craniofacial procedures), invasive diagnostic procedures (e.g., endoscopy), or major dental procedures (all patients should be informed of the higher risk of attacks during major dental procedures).
In addition to prophylaxis, patients should remain under observation for $36 \mathrm{~h}$ and should have easy access to rescue medication. ${ }^{5}$

Therapeutic intervention should be performed before the occurrence of events that can provoke HAE attacks. Favorable results have been obtained with the use of attenuated androgens, antifibrinolytic agents, fresh frozen plasma, and C1-INH concentrates (Table 6).

Fresh frozen plasma can be administered intravenously at a dose of $2 U$ the night before surgery or on the day of surgery (grade D recommendation). Epsilon-aminocaproic acid is effective when it is administered several days before the triggering event (grade $\mathrm{C}$ recommendation). Androgens, which have a grade $C$ recommendation, are used three-five days before surgery at doses of $10 \mathrm{mg} \cdot \mathrm{kg}^{-1} \cdot$ day $^{-1}$, with a maximum dose of $600 \mathrm{mg} /$ day. ${ }^{76}$ For prophylaxis in adults and children, $\mathrm{C} 1-\mathrm{INH}$ concentrates are safe and effective at doses of 500-1,000 U when administered intravenously (grade $\mathrm{C}$ recommendation). Some of these products have also been tested and are currently used in pregnant women.

Initially, in the 1970s, C1-INH concentrate was established as the emergency treatment for HAE. With the introduction of viral inactivation processes, $\mathrm{C} 1-\mathrm{INH}$ concentrate also became a first-line drug for the prophylaxis of acute HAE attacks. There are two C1-INH concentrates currently in use in the United States: Cinryze ${ }^{\circledR}$ and Berinert ${ }^{\circledR}$. Because of regulatory issues, Cinryze ${ }^{\circledR}$ is indicated for short-term prophylaxis of HAE but not for the treatment of attacks, and Berinert ${ }^{\circledR}$ is indicated for the treatment of acute HAE attacks.

\section{How should HAE attacks be treated?}

The treatment of acute HAE attacks depends on their severity (Table 7). Severe attacks and attacks involving the respiratory tract require urgent treatment because of the potential for morbidity and mortality.

Although episodes of peripheral edema rarely require treatment, the early administration of danazol can shorten the duration of attacks and uncomfortable symptoms (grade $\mathrm{D}$ recommendation). Patients who are taking attenuated androgens prophylactically should double the dose for a few days after identifying an attack in any part of the body. ${ }^{76}$ Therapy with antifibrinolytic agents, such as tranexamic acid administered orally every $3-4 \mathrm{~h}$, has also been recommended for mild crisis periods (grade C recommendation).

Abdominal attacks are extremely painful and can be accompanied by vomiting, diarrhea, or both. When patients present with severe abdominal attacks, symptomatic treatment with the administration of fluids, antiemetics, and analgesics is indicated. Antispasmodics and narcotics may be required to treat intense pain. ${ }^{37}$

Dysphonia and dysphagia are indicative of progression to a severe laryngeal attack. Such attacks develop slowly over the course of approximately $8 \mathrm{~h}$ on average, and dysphagia and voice changes generally precede laryngeal obstruction. ${ }^{16}$ However, there have been reports of rapid-onset laryngeal edema, and physicians should bear this in mind when evaluating such patients.

More severe cases require immediate intubation. In such cases, oxygen therapy is indicated, and pulse oximetry should be monitored. During laryngoscopy and intubation, the need for tracheostomy should be evaluated. ${ }^{77}$ In cases of laryngeal edema, it may be prudent to perform prophylactic 
Table 6 - Drugs used for the short-term prophylaxis and treatment of acute attacks of hereditary angioedema.

\begin{tabular}{|c|c|c|c|}
\hline Short-term prophylaxis & Trade name & Dose & Adverse events \\
\hline Tranexamic acid & $\begin{array}{l}\text { Transamin }^{\circledR} \\
\text { Hemoblock }^{\circledR}\end{array}$ & $\begin{array}{c}1 \mathrm{~g} \text { administered orally every } 4 \mathrm{~h} \text { (or } \\
0.5 \mathrm{~g} \text { administered intravenously } \\
\text { every } 4 \mathrm{~h} \text { ) for } 18 \mathrm{~h}\end{array}$ & Diarrhea \\
\hline High-dose attenuated androgens & $\begin{array}{l}\text { Danazol } \\
\text { Oxandrolone }\end{array}$ & $\begin{array}{c}10 \mathrm{mg} \cdot \mathrm{kg}^{-1} \cdot \mathrm{day}^{-1} \text { with a maximum } \\
\text { dose of } 600 \mathrm{mg} / \text { day for } 3-5 \text { days } \\
\text { before the procedure }\end{array}$ & $\begin{array}{c}\text { Weight gain, voice changes, } \\
\text { increased hair growth, and } \\
\text { menstrual irregularity }\end{array}$ \\
\hline $\begin{array}{l}\text { C1-INH concentrate* and recombinant } \\
\text { C1-INH* }\end{array}$ & $\begin{array}{l}\text { Berinert }{ }^{\circledR} \\
\text { Cinryze }^{\circledR}\end{array}$ & $\begin{array}{l}500-1,000 \mathrm{U} \text { on the day before the } \\
\text { procedure or on the day of the } \\
\text { procedure }\end{array}$ & - \\
\hline Fresh plasma & - & $10 \mathrm{ml} / \mathrm{kg}$ & Hyperosmolarity \\
\hline \multicolumn{4}{|l|}{ Treatment of acute attacks } \\
\hline C1-INH concentrate* and recombinant & Berinert ${ }^{\circledR}$ & $1,000 \mathrm{U}$ administered intravenously or & - \\
\hline C1-INH* & Cinryze ${ }^{\circledR}$ & $10-20 \mathrm{U} / \mathrm{kg}$ & \\
\hline Fresh plasma & - & $10 \mathrm{ml} / \mathrm{kg}$ & Hyperosmolarity \\
\hline Bradykinin receptor Antagonist & Icatibant $\left(\right.$ Firazyr $\left.{ }^{\circledR}\right)$ & $\begin{array}{c}30 \mathrm{mg} / \mathrm{dose} \text { and repeat an initial dose } \\
\text { and a second dose if the attack } \\
\text { persists }\end{array}$ & Local hyperemia \\
\hline Kallikrein inhibitor* & Ecallantide (Kalbitor ${ }^{\circledR}$ ) & $\begin{array}{l}20 \mathrm{U} / \mathrm{kg} \text { or } 30 \mathrm{mg} / \mathrm{dose} \text { and repeat the } \\
\text { second dose if the attack persists }\end{array}$ & Hypersensitivity reactions \\
\hline
\end{tabular}

*Drugs that have not yet been approved in Brazil.

intubation as an early measure to maintain airway patency and avoid tracheostomy (grade D recommendation). ${ }^{77}$

In cases of severe acute attacks, the treatment of choice is C1-INH replacement therapy, which can be achieved by the intravenous infusion of $1,000 \mathrm{U}$ of a $\mathrm{C} 1-\mathrm{INH}$ concentrate (grade A recommendation), by the infusion of recombinant C1-INH, or, as reported recently, by a kallikrein inhibitor or a BDKRB2 antagonist (grade B recommendation).

In countries where the aforementioned drugs are not available, fresh plasma or solvent/detergent-treated plasma, which contains C1-INH, can be used (grade D recommendation). However, this type of treatment can worsen HAE attacks because fresh plasma also contains the remaining complement, coagulation, and contact system components. In addition, there are concerns regarding the safety of fresh plasma (e.g., transfusion-related acute lung injury, anaphylaxis, and viral transmission), and the need for a relatively large volume of plasma might be problematic in an emergency setting or in patients who cannot tolerate significant volume expansion. Therefore, when C1-INH concentrate, or bradykinin receptor antagonist, or kallikrein inhibitor are available, they are preferred over plasma transfusion. ${ }^{37,78,79}$

The symptoms generally improve $30-40 \mathrm{~min}$ after the infusion of C1-INH concentrate. A second, identical, dose can be administered if necessary.
The fractional catabolic rate of $\mathrm{C} 1-\mathrm{INH}$ is $2.5 \%$ of the plasma pool per hour. However, in patients with HAE, the half-life of C1-INH is longer than predicted by the fractional catabolic rate $(>48 \mathrm{~h}$ vs. $28 \mathrm{~h})$. This difference is probably attributable to the observation that exogenous $\mathrm{C} 1-\mathrm{INH}$ reduces the consumption of endogenous $\mathrm{C} 1-\mathrm{INH}$, preventing C1 autoactivation. ${ }^{50,79,80}$

Rhucin ${ }^{\circledR}$, which was developed recently, is a recombinant C1-INH derived from the milk of transgenic rabbits. ${ }^{75}$ Although its half-life is only $3 \mathrm{~h}$, Rhucin ${ }^{\circledR}$ has been shown to produce a response similar to that produced by other commercially available $\mathrm{C} 1-\mathrm{INH}$ preparations in the treatment of HAE attacks (grade $\mathrm{B}$ recommendation). ${ }^{75,81}$ Further studies are needed to assess the effects of Rhucin.

In addition to $\mathrm{C} 1-\mathrm{INH}$ replacement therapy, blocking the synthesis and effects of bradykinin constitute other pharmacological approaches to HAE attacks. Recent studies have confirmed the efficacy of a kallikrein inhibitor and a BDKRB2 antagonist.

The BDKRB2 antagonist, icatibant, is highly specific for BDKRB2, binding to it with the same affinity as bradykinin and inhibiting a variety of BDKRB2-mediated effects. ${ }^{82}$ The drug is administered subcutaneously, and its plasma halflife is 2-4 h. Icatibant is degraded by peptidases, and the products of icatibant degradation are excreted by the

Table 7 - Parameters for the treatment of acute attacks in patients with hereditary angioedema. ${ }^{6,38}$

\begin{tabular}{|c|c|c|c|c|}
\hline \multirow{2}{*}{ Treatment } & \multicolumn{2}{|c|}{ Edema of the skin } & \multirow[t]{2}{*}{ Abdominal attack } & \multirow[t]{2}{*}{ Laryngeal edema } \\
\hline & Torso and extremities & Face and neck region & & \\
\hline Wait and see (spontaneous resolution) & \pm & - & - & - \\
\hline Tranexamic acid & + & + & + & + \\
\hline $\begin{array}{l}\text { C1-INH concentrate, } \\
\text { bradykinin receptor antagonist, } \\
\text { kallikrein inhibitor }\end{array}$ & \pm & + & + & + \\
\hline ICU (intubation/tracheostomy) & - & - & - & + \\
\hline
\end{tabular}

C1-INH: C1 inhibitor, ICU: intensive care unit.

+ indicated.

\pm consider indication.

- contraindicated. 
kidneys. Icatibant was initially shown to be effective in treating seasonal allergic rhinitis and asthma. Subsequently, two double-blind, randomized, multicenter trials (the For Angioedema Subcutaneous Treatment trial, parts 1 and 2) found that a single dose of icatibant was effective in $90 \%$ of the attacks of HAE (grade $\mathrm{B}$ recommendation). ${ }^{83}$ One perspective that merits investigation is the home treatment of HAE attacks with icatibant. Icatibant has been approved in Brazil, and its use is indicated for the treatment of HAE attacks. Although the drug can be stored at room temperature, in Brazil, it is suggested that the drug be stored at $4{ }^{\circ} \mathrm{C}$.

Ecallantide is a high-potency recombinant protease inhibitor that binds to and inhibits kallikrein, thus decreasing bradykinin production. Because of its short half-life when it is administered subcutaneously, ecallantide has been evaluated for use in acute HAE attacks only. Multicenter phase III clinical trials have found a significant reduction in the severity of acute attacks after ecallantide administration compared to a placebo (grade B recommendation). ${ }^{84}$ Side effects were rare and included dyspnea, oropharyngeal edema, and prolonged prothrombin and thrombin times. There have also been isolated reports of anaphylactic reactions following ecallantide administration; therefore, the use of the drug is restricted to hospital environments. $^{85}$

To date, no studies been conducted to compare the efficacy of C1-INH concentrate, icatibant, and ecallantide in the treatment of HAE attacks. ${ }^{86}$

Regarding pharmacological treatment, it should be highlighted that, unlike anaphylaxis and edemas associated with the degranulation of mast cells and basophils, C1-INH deficiency-induced angioedema does not respond significantly to the administration of antihistamines, glucocorticoids, or epinephrine. ${ }^{77}$

\section{SPECIAL SITUATIONS}

\section{Pediatric patients}

In pediatric patients, antifibrinolytic agents are the drugs of choice for long-term prophylaxis because of their safety profiles (grade $\mathrm{C}$ recommendation). Studies have reported that tranexamic acid is better tolerated than epsilonaminocaproic acid. When these agents are not sufficient, attenuated androgens may be required. The use of minimum maintenance doses for control has been found to have no negative impact on growth, and the only adverse effect that was observed was late menarche with subsequent menstrual irregularity, which was attributed to the use of danazol (200 mg/day). ${ }^{87}$

During the first two years of prophylaxis, it is recommended that laboratory tests be performed every three-four months and that abdominal ultrasounds be performed every six months. The clinical course of HAE should be monitored, as should any adverse effects of treatment.

\section{Pregnancy and delivery}

During pregnancy and, if possible, even before conception, the ideal situation is that no prophylactic drug be used. Attenuated androgens are contraindicated, and tranexamic acid can be used if it is administered with caution (grade $\mathrm{C}$ recommendation).

The treatment of HAE attacks does not change during pregnancy. Attacks during vaginal delivery are rare. However, when they do occur, they are severe. Regional analgesia is recommended for surgical delivery; general anesthesia and orotracheal intubation should be avoided (grade $\mathrm{C}$ recommendation).

\section{Suspected cases of acute abdomen}

Some HAE attacks mimic acute surgical abdomen, and negative exploratory laparotomy results are common in such patients. ${ }^{20,21}$ However, a diagnosis of HAE raises the concern that if there is a true abdominal emergency requiring surgery, the timing of the surgical procedure may be delayed.

\section{CONCLUSION}

The Experts in Clinical Immunology and Allergy of the "Associação Brasileira de Alergia e Imunopatologia ASBAI" developed these guidelines for the diagnosis, therapy, and management of hereditary angioedema. We hope that these guidelines will aid readers in the diagnosis and treatment of HAE, which is a neglected disease. A Portuguese version of this consensus is published in the "Revista Brasileira de Alergia e Imunopatologia". 88

\section{REFERENCES}

1. Quincke HI. Über akutes umschriebenes Hautödem. Monatsh Prakt Dermatol. 1882;1:129-31.

2. Osler W. Hereditary angioneurotic edema. Am J Med Sci. 1888;95:362-7, doi: 10.1097/00000441-188804000-00004.

3. Donaldson VH, Evans RR. A biochemical abnormality in hereditary angioneurotic edema: absence of serum inhibitor of $C^{\prime} 1$-esterase. Am J Med. 1963;35:37-44, doi: 10.1016/0002-9343(63)90162-1.

4. Freiberger $\mathrm{T}$, Kolárová L, Mejstrík $\mathrm{P}$, Vyskocilová $\mathrm{M}$, Kuklínek $\mathrm{P}$ Litzman J. Five novel mutations in the $\mathrm{C} 1$ inhibitor gene $(\mathrm{C} 1 \mathrm{INH})$ leading to a premature stop codon in patients with type I hereditary angioedema. Hum Mutat. 2002;19:461, doi: 10.1002/humu.9029.

5. Gompels MM, Lock RJ, Abinun M, Bethune CA, Davies G, Grattan C, et al. C1 inhibitor deficiency: consensus document. Clin Exp Immunol. 2005;139:379-94, doi: 10.1111/j.1365-2249.2005.02726.x.

6. Bowen T, Cicardi M, Bork K, Zuraw B, Frank M, Ritchie B, et al. Hereditary angioedema: a current state-of-the-art review, VII: Canadian Hungarian 2007 International Consensus Algorithm for the Diagnosis, Therapy, and Management of Hereditary Angioedema. Ann Allergy Asthma Immunol. 2008;100(1Suppl 2):S30-40, doi: 10.1016/S10811206(10)60584-4.

7. Agostoni A, Cicardi M. Hereditary and acquired C1-inhibitor deficiency: biological and clinical characteristics in 235 patients. Medicine (Baltimore). 1992;71:206-15.

8. Pappalardo E, Cicardi M, Duponchel C, Carugati A, Choquet S, Agostoni $\mathrm{A}$, et al. Frequent de novo mutations and exon deletions in the $\mathrm{C} 1$ inhibitor gene of patients with angioedema. J Allergy Clin Immunol. 2000;106:1147-54, doi: 10.1067/mai.2000.110471.

9. Bouillet L. Hereditary angioedema in women. Allergy Asthma Clin Immunol. 2010;6:17, doi: 10.1186/1710-1492-6-17

10. Cicardi M, Bergamaschini L, Marasini B, Boccassini G, Tucci A, Agostoni A. Hereditary angioedema: an appraisal of 104 cases. Am J Med Sci. 1982;284:2-9, doi: 10.1097/00000441-198207000-00001.

11. Bork K, Meng G, Staubach P, Hardt J. Hereditary Angioedema: New Findings Concerning Symptoms, Affected Organs, and Course. Am J Med. 2006;119:267-74, doi: 10.1016/j.amjmed.2005.09.064.

12. Tanno LK, Pinto LH, Motta AA, Kalil J, Giavina-Bianchi P. Hereditary Angioedema: Clinical Characteristics and Outcome of 36 Patients. J Allergy Clin Immunol. 2007;119(1S):S275, doi: 10.1016/j.jaci.2006.12. 445 .

13. Grumach AS. Angioedema Hereditário, EPM, São Paulo. 2008.

14. Fay A, Abinun M. Current management of hereditary angio-oedema $\left(C^{\prime} 1\right.$ esterase inhibitor deficiency). J Clin Pathol. 2002;55:266-70, doi: 10.1136/ jcp.55.4.266.

15. Bork K, Hardt J, Schicketanz KH, Ressel N. Clinical studies of sudden upper airway obstruction in patients with hereditary angioedema due to C1 esterase inhibitor deficiency. Arch Intern Med. 2003;163:1229-35, doi: 10.1001/archinte.163.10.1229.

16. Moore GP, Hurley WT, Pace SA. Hereditary angioedema. Ann Emerg Med. 1988;17:1082-6, doi: 10.1016/S0196-0644(88)80450-5.

17. Lumry WR, Castaldo AJ, Vernon MK, Blaustein MB, Wilson DA, Horn PT. The humanistic burden of hereditary angioedema: Impact on 
health-related quality of life, productivity, and depression. Allergy Asthma Proc. 2010;31:407-14, doi: 10.2500/aap.2010.31.3394.

18. Bygum A, Andersen KE, Mikkelsen CS. Self-administration of intravenous C1-inhibitor therapy for hereditary angioedema and associated quality of life benefits. Eur J Dermatol. 2009;19:147-51.

19. Winnewisser J, Rossi M, Späth $P$, Bürgi $H$. Type 1 hereditary angiooedema. Variability of clinical presentation and course within two large kindreds. J Inter Med. 1997;241:39-46, doi: 10.1046/j.1365-2796.1997. 76893000.x.

20. Bork K, Staubach P, Eckardt AJ, Hardt J. Symptoms, course, and complications of abdominal attacks in hereditary angioedema due to $\mathrm{C} 1$ inhibitor deficiency. Am J Gastroenterol. 2006;101:619-27, doi: 10.1111/j. 1572-0241.2006.00492.x

21. Farkas H, Harmat G, Kaposi PN, Karádi I, Fekete B, Füst G, et al. Ultrasonography in the diagnosis and monitoring of ascites in acute abdominal attacks of hereditary angioneurotic oedema. Eur J Gastroenterol Hepatol. 2001;13:1225-30, doi: 10.1097/00042737-200110000-00016.

22. Rosen FS, Pensky J, Donaldson V, Charache P. Hereditary angioneurotic edema: two genetic variants. Science. 1965;148:957-8, doi: 10.1126/ science.148.3672.957.

23. Ziccardi RJ. Spontaneous activation of the first component of human complement (C1) by an intramolecular autocatalytic mechanism. J Immunol. 1982;128:2500-4.

24. Fields T, Ghebrehiwet B, Kaplan AP. Kinin formation in hereditary angioedema plasma: evidence against kinin derivation from $\mathrm{C} 2$ and in support of "spontaneous" formation of bradykinin. J Allergy Clin Immunol. 1983;72:54-60, doi: 10.1016/0091-6749(83)90052-0.

25. Nussberger J, Cugno M, Amstutz C, Cicardi M, Pellacani A, Agostoni A. Plasma bradykinin in angio-oedema. Lancet. 1998;351:1693-7, doi: 10. 1016/S0140-6736(97)09137-X.

26. Han ED, MacFarlane RC, Mulligan AN, Scafidi J, Davis AE 3rd. Increased vascular permeability in $\mathrm{C} 1$ inhibitor-deficient mice mediated by the bradykinin type 2 receptor. J Clin Invest. 2002;109:1057-63.

27. Nussberger J, Cugno M, Cicardi M. Bradykinin-mediated angioedema. N Engl J Med. 2002;347:621-2, doi: 10.1056/NEJM200208223470820.

28. Zuraw BL, Herschbach J. Detection of $\mathrm{C} 1$ inhibitor mutations in patients with hereditary angioedema. J Allergy Clin Immunol. 2000;105:541-6, doi: $10.1067 /$ mai.2000.104780

29. Bowen B, Hawk JJ, Sibunka S, Hovick S, Weiler JM. A review of the reported defects in the human $\mathrm{C} 1$ esterase inhibitor gene producing hereditary angioedema including four new mutations. Clin Immunol. 2001;98:157-63, doi: 10.1006/clim.2000.4947.

30. Bork K, Barnstedt SE, Koch P, Traupe H. Hereditary angioedema with normal C1-inhibitor activity in women. Lancet. 2000;356:213-7, doi: 10. 1016/S0140-6736(00)02483-1.

31. Cichon S, Martin L, Hennies HC, Müller F, Van Driessche K, Karpushova A, et al. Increased activity of coagulation factor XII (Hageman Factor) causes hereditary angioedema type III. Am J Hum Genet. 2006;79:1098104, doi: $10.1086 / 509899$.

32. Serrano C, Guilarte M, Tella R, Dalmau G, Bartra J, Gaig P, et al. Oestrogen-dependent hereditary angio-oedema with normal C1 inhibitor: description of six new cases and review of pathogenic mechanisms and treatment. Allergy. 2008;63:735-41, doi: 10.1111/j.1398-9995.2007. 01579.x.

33. Sheffer AL, Austen KF, Rosen FS, Fearon DT. Acquired deficiency of the inhibitor of the first component of complement: report of five additional cases with commentary on the syndrome. J Allergy Clin Immunol. 1985;75:640-6, doi: 10.1016/0091-6749(85)90087-9.

34. Cugno M, Castelli R, Cicardi M. Angioedema due to acquired C1inhibitor deficiency: a bridging condition between autoimmunity and lymphoproliferation. Autoimmun Rev. 2008;8:156-9, doi: 10.1016/j. autrev.2008.05.003.

35. Marín García D, Ceballos Torres A, Ruiz Serrato A, García Ordóñez MÁ. Acute pancreatitis associated with hereditary angioedema. Gastroenterol Hepatol. 2010;33:633-7, doi: 10.1016/j.gastrohep.2010.07.005.

36. Agostoni A, Aygören-Pürsün E, Binkley KE, Blanch A, Bork K, Bouillet L, et al. Hereditary and acquired angioedema: problems and progress: proceedings of the third $\mathrm{C} 1$ esterase inhibitor deficiency workshop and beyond. J Allergy Clin Immunol. 2004;114:S51-131, doi: 10.1016/j.jaci. 2004.06.047.

37. Bowen T, Cicardi M, Farkas H, Bork K, Kreuz W, Zingale L, et al. Canadian 2003 International Consensus Algorithm For the Diagnosis, Therapy, and Management of Hereditary Angioedema. J Allergy Clin Immunol. 2004;114:629-37, doi: 10.1016/j.jaci.2004.06.043.

38. Bowen T, Cicardi M, Farkas H, Bork K, Longhurst HJ, Zuraw B, et al. 2010 International consensus algorithm for the diagnosis, therapy and management of hereditary angioedema. Allergy Asthma Clin Immunol. 2010;6:24, doi: 10.1186/1710-1492-6-24.

39. França AT, Valle SOR. Urticária e Angioedema. $2^{\text {a }}$ edição. Editora Revinter, RJ. 2006;p193.

40. Jorge AS, Dortas SD, Valle SO, França AT. Hereditary angioedema and chronic urticaria: is there a possible association? J Investig Allergol Clin Immunol. 2009;19:327-8.
41. Farkas H, Varga L, Széplaki G, Visy B, Harmat G, Bowen T. Management of hereditary angioedema in pediatric patients. Pediatrics. 2007;120:e71322, doi: 10.1542 /peds.2006-3303.

42. Cicardi M, Zanichelli A. Acquired angioedema. Allergy Asthma Clin Immunol. 2010;6:14, doi: 10.1186/1710-1492-6-14

43. Centers for Disease Control (CDC). Recommendation of the Immunization Practices Advisory Committee (ACIP). Inactivated hepatitis B virus vaccine. MMWR Morb Mortal Wkly Rep. 1982;31:31722,27-8.

44. Byrd JB, Adam A, Brown NJ. Angiotensin-converting enzyme inhibitor associated angioedema. Immunol Allergy Clin North Am. 2006;26:72537, doi: 10.1016/j.iac.2006.08.001.

45. Schuster C, Reinhart WH, Hartmann K, Kuhn M. Angioedema induced by ACE inhibitors and angiotensin II-receptor antagonists: analysis of 98 cases. Schweiz Med Wochenschr. 1999;129:362-9.

46. Bork K, Fischer B, Dewald G. Recurrent episodes of skin angioedema and severe attacs of abdominal pain induced by oral contraceptives or hormone replacement therapy. Am J Med. 2003;114:294-8, doi: 10.1016/ S0002-9343(02)01526-7.

47. Brown NJ, Byiers S, Carr D, Maldonado M, Warner BA. Dipeptidyl peptidase-IV inhibitor use associated with increased risk of ACE inhibitor-associated angioedema. Hypertension. 2009;54:516-23, doi: 10. 1161/HYPERTENSIONAHA.109.134197.

48. Farkas H. Pediatric hereditary angioedema due to C1-inhibitor deficiency. Allergy Asthma Clin Immunol. 2010;6:18, doi: 10.1186/1710-14926-18.

49. Kamboj S, Lillis RA, Wegmann M, Wild LG, Lopez FA, Kumar P. Hereditary angioedema: a rare but potentially lethal disease. J La State Med Soc. 2002;154:121-4

50. Zuraw BL. Hereditary angioedema: a current state-of-the-art review, IV: short-and long-term treatment of hereditary angioedema: out with the old and in with the new? Ann Allergy Asthma Immunol. 2008;1001Suppl 2:S13-8, doi: 10.1016/S1081-1206(10)60581-9.

51. Gelfand JA, Sherins RJ, Alling DW, Frank MM. Treatment of hereditary angioedema with danazol. N Engl J Med. 1976;295:1444-8, doi: 10.1056/ NEJM197612232952602.

52. Church JA. Oxandrolone treatment of childhood angioedema. Ann Allergy Asthma Immunol. 2004;92:377-8, doi: 10.1016/S10811206(10)61578-5.

53. MacFarlane JT, Davies D. Management of hereditary angio-oedema with low-dose danazol. Br Med J (Clin Res Ed). 1981;282:1275, doi: 10.1136/ bmj.282.6272.1275.

54. Hosea SW, Santaella ML, Brown EJ, Berger M, Katusha K, Frank MM. Long term therapy of hereditary angioedema with danazol Ann Intern Med. 1980;93:809-12.

55. Frank MM. Hereditary angioedema: the clinical syndrome and its management in the United States. Immunol Allergy Clin North Am. 2006;26:653-68, doi: 10.1016/j.iac.2006.09.005.

56. Cicardi M, Castelli R, Zingale LC, Agostoni A. Side effects of long-term prophylaxis with attenuated androgens in hereditary angioedema: comparison of treated and untreated patients. J Allergy Clin Immunol. 1997;99:194-6, doi: 10.1016/S0091-6749(97)70095-2.

57. Széplaki G, Varga L, Valentin S, Kleiber M, Karádi I, Romics L, et al Adverse effects of danazol prophylaxis on the lipid profiles of patients with hereditary angioedema. J Allergy Clin Immunol. 2005;115:864-9, doi: 10.1016/j.jaci.2004.12.1130

58. Szegedi R, Széplaki G, Varga L, Prohászka Z, Széplaki Z, Karádi I, et al. Long-term danazol prophylaxis does not lead to increased carotid intima-media thickness in hereditary angioedema patients. Atherosclerosis. 2008;198:184-91, doi: 10.1016/j.atherosclerosis.2007.09. 025.

59. Birjmohun RS, Kees Hovingh G, Stroes ES, Hofstra JJ, Dallinga-Thie GM, Meijers JC, et al. Effects of short-term and long-term danazol treatment on lipoproteins, coagulation, and progression of atherosclerosis: two clinical trials in healthy volunteers and patients with hereditary angioedema. Clin Ther. 2008;12:2314-23, doi: 10.1016/j.clinthera.2008. 12.021 .

60. Zurlo JJ, Frank MM. The long-term safety of danazol in women with hereditary angioedema. Fertil Steril. 1990;54:64-72.

61. Bork K, Pitton M, Harten P, Kock P. Hepatocellular adenomas in patients taking danazol for hereditary angio-oedema. Lancet. 1999;353:1066-7, doi: 10.1016/S0140-6736(99)00110-5.

62. Monnier N, Ponard D, Duponchel C, Csopaki F, Bouillet L, Tosi M, et al. Characterisation of a new C1 inhibitor mutant in a patient with hepatocellular carcinoma. Mol Immunol. 2006;43:2161-8, doi: 10.1016/j. molimm.2006.01.006.

63. Farkas H, Czaller I, Csuka D, Vas A, Valentin S, Varga L, et al. The effect of long-term danazol prophylaxis on liver function in hereditary angioedema in hereditary angioedema-a longitudinal study. Eur J Clin Pharmacol. 2010;66:419-26, doi: 10.1007/s00228-009-0771-z.

64. Brunskill PJ. The effects of fetal exposure to Danazol. Br J Obstet Gynaecol. 1992;99:212-5, doi: 10.1111/j.1471-0528.1992.tb14501.x.

65. Schwartz R. Ambiguous genitalia in a term female infant due to exposure to danazol in utero. Am J Dis Child. 1982;136:474. 
66. Castro-Magana M, Cheruvanky T, Collipp PJ, Ghavami-Maibodi Z, Angulo M, Stewart C. Transient adrenogenital syndrome due to exposure to danazol in utero. Am J Dis Child. 1981;135:1032-4

67. Frank MM, Sergent JS, Kane MA, Alling DW. Epsilon aminocaproic acid therapy of hereditary angioneurotic edema: A double-blind study. N Engl J Med. 1972;286:808-12, doi: 10.1056/NEJM197204132861503.

68. Sheffer AL, Austen KF, Rosen FS. Tranexamic acid therapy in hereditary angioneurotic edema. N Engl J Med. 1972;287:452-4, doi: 10.1056/ NEJM197208312870907.

69. Blohmé G. Treatment of hereditary angioneurotic oedema with tranexamic acid. A random double-blind cross-over study. Acta Med Scand. 1972;192:293-8.

70. Champion RH, Lachmann PJ. Hereditary angio-oedema treated with Eaminocaproic acid. Br J Dermatol. 1969;81:763-5, doi: 10.1111/j.13652133.1969.tb15938.x.

71. Nilsson IM, Andersson L, Björkman SE. Epsilon-aminocaproic acid (EACA) as a therapeutic agent based on 5 year's clinical experience. Acta Med Scand Suppl. 1966;448:1-46.

72. Sheffer AL, Fearon DT, Austen KF, Rosen FS. Tranexamic acid: preoperative prophylatic therapy for patients with hereditary angioneurotic edema. J Allergy Clin Immunol. 1977;60:38-40, doi: 10.1016/ 0091-6749(77)90080-X.

73. Bork K, Hardt J. Hereditary angioedema: long-term treatment with one or more injections of $\mathrm{C} 1$ inhibitor concentrate per week. Int Arch Allergy Immunol. 2011;154:81-8, doi: 10.1159/000319213.

74. Tallroth GA. Long-Term Prophylaxis of Hereditary Angioedema with a Pasteurized C1 Inhibitor Concentrate. Int Arch Allergy Immunol. 2010;154:356-359, doi: 10.1159/000321830.

75. Zuraw BL, Busse PJ, White M, Jacobs J, Lumry W, Baker J, et al. Nanofiltered C1 inhibitor concentrate for treatment of hereditary angioedema. N Engl J Med. 2010;363:513-22, doi: 10.1056/ NEJMoa0805538.

76. Banerji A, Sloane DE, Sheffer AL. Hereditary Angioedema: a current state-of-the-art review, V: attenuated androgens for the treatment of hereditary angioedema. Ann Allergy Asthma Immunol. 2008;(100 1Suppl 2):S19-22, doi: 10.1016/S1081-1206(10)60582-0.
77. Jensen NF, Weiler JM. C1 esterase inhibitor deficiency, airway compromise, and anesthesia. Anesth Analg. 1998;87:480-8.

78. Sheffer AL. Hereditary angioedema: optimal therapy. J Allergy Clin Immunol. 2007;120:756-7, doi: 10.1016/j.jaci.2007.08.010.

79. Bernstein JA. Hereditary angioedema: a current state-of-the-art review, VIII: current status of emerging therapies. Ann Allergy Asthma Immunol. 2008;100 1Suppl 2:S41-6, doi: 10.1016/S1081-1206(10)60585-6.

80. Farkas H, Jakab L, Temesszentandrási G, Visy B, Harmat G, Füst G, et al. Hereditary angioedema: a decade of human C1-inhibitor concentrate therapy. J Allergy Clin Immunol. 2007;120:941-7, doi: 10.1016/j.jaci.2007. 06.026 .

81. Lock RJ, Gompels MM. C1-inhibitor deficiencies (hereditary angioedema): where are we with therapies? Curr Allergy Asthma Rep. 2007;7:264-9, doi: 10.1007/s11882-007-0039-6.

82. Bork K, Frank J, Grundt B, Schlattmann P, Nussberger J, Kreuz W. Treatment of acute edema attacks in hereditary angioedema with a bradykinin receptor-2 antagonist (Icatibant). J Allergy Clin Immunol. 2007;119:1497-503, doi: 10.1016/j.jaci.2007.02.012.

83. Cicardi M, Banerji A, Bracho F, Malbrán A, Rosenkranz B, Riedl M, et al. Icatibant, a new bradykinin-receptor antagonist, in hereditary angioedema. N Engl J Med. 2010;363:523-31, doi: 10.1056/NEJMoa0905079.

84. Cicardi M, Levy RJ, McNeil DL, Li HH, Sheffer AL, Campion MMS, et al. Ecallantide for the treatment of acute attacks in hereditary angioedema. N Engl J Med. 2010;363:532-41, doi: 10.1056/NEJMoa0906393.

85. Frank MM. Hereditary angioedema: a current state-of-the-art review, VI: novel therapies for hereditary angioedema. Ann Allergy Asthma Immunol. 2008;100 1Suppl 2:S23-9, doi: 10.1016/S1081-1206(10)60583-2.

86. Giavina-Bianchi P, Motta A, Kalil J. Therapeutic agents for hereditary angioedema. N Engl J Med. 2011;364:84-6, doi: 10.1056/NEJMc1010085.

87. Farkas H, Harmat G, Füst G, Varga L, Visy B. Clinical management of hereditary angio-oedema in children. Pediatr Allergy Immunol. 2002;13:153-61, doi: 10.1034/j.1399-3038.2002.01014.x.

88. Giavina-Bianchi P, França AT, Grumach AS, Motta AA, Fernandes FR, Campos RA, et al. Diretrizes do diagnóstico e tratamento do angioedema hereditário. Revista Brasileira de Alergia e Imunopatologia. 2010;33:241252. 